\title{
Towards a national sports safety strategy: addressing facilitators and barriers towards safety guideline uptake
}

\author{
Caroline F Finch, ${ }^{1}$ Belinda J Gabbe, ${ }^{2}$ David G Lloyd, ${ }^{3}$ Jill Cook, ${ }^{4}$ Warren Young, ${ }^{5}$ \\ Matthew Nicholson, ${ }^{6}$ Hugh Seward, ${ }^{7}$ Alex Donaldson, ${ }^{1}$ Tim L A Doyle ${ }^{8}$
}

${ }^{1}$ Australian Centre for Research into Injury in Sport and its Prevention (ACRISP), Monash Injury Research Institute (MIRI) Monash University, Clayton, Victoria, Australia

${ }^{2}$ Department of Epidemiology and Preventive Medicine, Monash University, The Alfred Hospital, Melbourne, Victoria, Australia

${ }^{3}$ Musculoskeletal Research Program, Griffith Health Institute, Griffith University, Gold Coast Campus, Queensland, Australia

${ }^{4}$ Department of Physiotherapy, School of Primary Health Care Monash University, Frankston, Victoria, Australia

${ }^{5}$ School of Human Movement and Sport Sciences, University of Ballarat, Ballarat, Victoria, Australia

${ }^{6}$ Centre for Sport and Social Impact, La Trobe University, Bundoora, Victoria, Australia ${ }^{7}$ Australian Football League (AFL) Medical Officers Association, AFL, Docklands, Victoria, Australia

${ }^{8}$ Human Protection and Performance Division, Defence Science Technology Organisation, Fishermens Bend, Victoria, Australia

\section{Correspondence to} Professor Caroline F Finch, Australian Centre for Research into Injury in Sport and its Prevention (ACRISP), Monash Injury Research Institute (MIRI), Monash University, Clayton Campus, Melbourne, Victoria, Australia;

caroline.finch@monash.edu

Accepted 5 January 2011

Published Online First

22 February 2011

\section{ABSTRACT}

Background Limited information exists about how best to conduct intervention implementation studies in community sport settings. Research should be directed towards understanding the context within which evidence-based injury prevention interventions are to be implemented, while continuing to build the evidencebase for the effectiveness of sports injury interventions. Objectives To identify factors that influence the translation of evidence-based injury prevention interventions into practice in community sport, and to provide specific evidence for the effectiveness of an evidence-based exercise training programme for lower limb injury prevention in community Australian football. Setting Community-level Australian football clubs, teams and players.

Methods An exercise-based lower limb injury prevention programme will be developed and evaluated in terms of the implementation context, infrastructure and resources needed for its effective translation into community sport. Analysis of the community sports safety policy context will be undertaken to understand the barriers and facilitators to policy development and uptake. A randomised group-clustered ecological study will be conducted to compare the reach, effectiveness, adoption, implementation and maintenance (RE-AIM) of the intervention over 2 years.

Outcome Measures The primary outcome will be evidence-based prevention guidelines that are fully supported by a comprehensively evaluated dissemination plan. The plan will detail the support structures and add-ons necessary to ensure sustainability and subsequent national implementation. Research outcomes will include new knowledge about how sports safety policy is set, how consensus is reached among sports safety experts in the community setting and how evidence-based safety guidelines are best developed, packaged and disseminated to community sport.

Because this project aims to significantly reduce a number of gaps (including the research to policy and practice gap, the efficacy to effectiveness gap, the research knowledge to translation gap and the gap between elite sport and community sport) within the context of player safety in Australian football, this project is to be known as the National Guidance for Australian football Partnerships and Safety (NoGAPS) Project.

The study is funded through a nationally competitive research grant through the (Australian) National Heath and Medical Research Council
(NHMRC) partnership project grant scheme over 2010-14, inclusive.

\section{STUDY OBJECTIVES}

This project will use an evidence-informed approach to develop and deliver a sports safety programme and evaluate the resources needed for its effective uptake in community sport. The NoGAPS Project responds to a recent sports safety policy analysis, which found that the needs of state sports bodies are different from those of government departments/non-government organisations. It was concluded that safety policy development must address the needs of all groups and that understanding the needs of different policy sectors is vital for the successful translation of sports injury prevention research evidence into safety policy and practice. In particular, the policy context analysis identified that sports organisations want practical guidance to help them adopt a sustainable approach to safety and to implement specific interventions. The NoGAPS Project builds on the current activities of our partner agencies and will include an assessment of the implementation of their existing strategies to develop a plan for strengthening them in the future.

While the strategic vision of the NoGAPS Project covers a range of sports and actions, a sports safety programme will be specifically developed, delivered and evaluated within community Australian football. The Australian football safety programme will comprise evidence-informed guidelines for preventing lower limb injuries, a comprehensive and tested dissemination plan and necessary support structures and add-ons to ensure its sustainability and subsequent national implementation. A detailed analysis of the community Australian football safety policy context will enable understanding of barriers and facilitators to policy development and uptake, and will inform the development of similar policy in other sports.

The NoGAPS Project will achieve this by:

1. Bringing together key agencies with a stakeholder interest in sports safety policy development and translation of scientific evidence to informed safety practice for the first time.

2. Developing new insights into the processes of developing sports safety strategy and policy.

3. New understanding of how sports bodies, government agencies and non-government organisations identify and package evidence into practical and useful safety guidelines, as a means of translating this evidence to practice. 
4. Obtaining new insights into the drivers of, and barriers towards, the successful dissemination and uptake of sports safety interventions in the context of community sport.

5. Developing an understanding of the policy context of community sport and how this could be better harnessed for public health benefits.

6. Assessing the reach, effectiveness, adoption, implementation and maintenance of a sport-specific safety intervention and identifying any necessary broad policy and organisational structures to support this.

7. Generating a strategic approach to inform the future implementation of evidence-based sports safety policy by the partner agencies for community sport nationally/statewide.

\section{THE PARTNERSHIP}

The problem of sports injuries has long been recognised by Commonwealth and state departments responsible for sport and health. ${ }^{23}$ Although the solutions are known to be multifaceted, requiring a broad intra and intersector approach, ${ }^{2}$ there is yet to be a concerted and coordinated effort to reduce the magnitude and frequency of the burden in Australia. A reason for this is that different key stakeholders within the relevant sectors have individually approached the problem from different perspectives, with contrasting priorities, and so it has been hard to reach consensus about the best approach to take. Moreover, much sports injury research to date has focused solely on risk identification, counting and describing the injury problem, identifying injury causes and developing potential injury prevention measures. Researchers have largely ignored the issue of how best to translate research evidence into effective interventions, so there is a major gap in the international literature about how to engage sports bodies in sports safety action. ${ }^{4}$ Consequently, there is very little guidance to inform decisionmaking or for identifying appropriate implementation strategies in community sport. To make sport safe for all participants, sports bodies and other key stakeholder groups need to formulate and implement safety policies jointly to reduce the risks of injury.

An effective public health response to sports injury requires a multi-agency approach. ${ }^{2} 3$ This project will be the first to bring together the full range of stakeholder groups to tackle the problem of community sports safety in Australia. To make a substantial difference, it is necessary to bring together a group of this size and representation. Given the low levels of investment in sports injury prevention to date, the cash and in-kind contributions provided by the partner agencies to this project represent major new investments in this area. Although some of our partners have a strong history of working together, this project provides an exciting and significant opportunity to forge new links and to contribute jointly to an innovative and strategic approach to sports safety.

This protocol has received major funding from the NHMRC through its NHMRC partnerships project grant scheme, as well as several partner agencies. The protocol was therefore developed collaboratively by all researchers and partners. Much of the NoGAPS Project's identified strategic need, and the specific context of its development (in Australian football), were suggested by our partners. The partners and their major role in safety policy and dissemination are:

1. The Australian Football League (AFL)-the national non-government organisation responsible for the delivery of Australian football, including the setting of all safety rules, policies and practices specifically for this sport. It covers all levels of play from professional athletes to community participants and children. (Visit the AFL general website: http://www.afl.com.au/ or the community football site http:// www.aflcommunityclub.com.au/ for further information).

2. The Victorian Health Promotion Foundation (VicHealth)a statutory body, and the world's first health promotion foundation, VicHealth has a mandate that includes encouraging, facilitating and supporting sustained participation in sport/physical activities, including through the removal of barriers to participation such as injury. (Visit http://www. vichealth.vic.gov.au/ for more information).

3. The New South Wales Sporting Injuries Committee (NSWSIC) - a NSW non-profit statutory organisation that provides serious injuries insurance and promotes injury prevention and safe sport practices across New South Wales. (Visit http://www.sportinginjuries.com.au/ for more details).

4. Jardine, Lloyd, Thompson Australia Sport (JLT Sport)-the major sports insurance broker agency in Australia, providing insurance cover for many sports nationally, including Australian football. It has invested significantly in risk management approaches for sports safety as a means of reducing insurance premiums by improving community sports safety leading to fewer insurance claims. (Visit http://www.jltsport.com.au/ for more information).

5. Department for Planning and Community DevelopmentSport and Recreation Victoria division (SRV) - the Victorian state government body responsible for providing strategic leadership, funding and support to the sport and recreation industry to improve facilities and increase community participation in sport and active recreation. (Visit http:// www.dpcd.vic.gov.au/sport for more information).

6. Sports Medicine Australia (SMA)-a not-for-profit nongovernment organisation that is Australia's peak sports medicine authority and professional body. This group: (a) trains those involved in sports first aid who address injury problems as they arise on sporting fields; (b) advocates for sports safety; (c) provides professional development opportunities for professionals engaged in all aspects of sports safety; (d) develops and disseminates guidelines on a range of sports safety issues; and (e) delivers Smartplay, the national sports safety programme (http://www.smartplay.com.au/ $\mathrm{Pub} / \mathrm{pStart} . \mathrm{asp}$ ). The project is partnering with both the national body (visit http://sma.org.au/ for more information) and the Victorian state branch (visit http://sma.org.au/ sma-branches-new/vic/ for more information).

\section{OVERVIEW OF APPROACH}

This project is underpinned by the translating research into injury prevention practice (TRIPP) framework that argues that future advances in sports injury prevention will only be achieved if research efforts are directed towards understanding the context of the implementation for injury prevention, as well as continuing to build the evidence-base for the efficacy and effectiveness of interventions. ${ }^{4}$ Randomised controlled trials (RCT) identifying efficacious interventions are not enough. If interventions cannot also be demonstrated to be widely adopted and sustained, then it is unlikely that they will have a public health impact. The corollary is that if the evidence-based interventions' fundamental injury reduction strategies are not included in adopted behaviours, the public health impact will also be ineffective. This means there needs to be clear understanding and linking of the intervention fundamentals and how to have these adopted.

Because of the lack of international and local implementation research, ${ }^{4-6}$ there is very little information about how best to 
conduct intervention studies in community sport settings. Application of health promotion frameworks to evaluate the public health impact of interventions could potentially help to improve our understanding of contextual and policy influences in this setting. Therefore, this project's design and analysis plan is based on the reach, effectiveness, adoption, implementation and maintenance (RE-AIM) health promotion framework and its domains of reach, effectiveness, adoption, implementation and maintenance. ${ }^{7}$ This framework has previously been used with individually targeted behaviour change through exercise programmes for elderly falls prevention ${ }^{9}$ and people with arthritis, ${ }^{10}$ lifestyle interventions targeting cardiovascular disease risk factors ${ }^{11}$ and other community-based behavioural interventions. ${ }^{12}$ More recently, the RE-AIM framework has been extended to meet the needs of interventions in community sport settings, ${ }^{13}$ forming the basis of this project.

This project will identify the factors that influence the translation of evidence into practice in the context of community-level Australian football. It will also provide specific evidence for the effectiveness of an evidence-based lower limb injury prevention exercise-training programme for community Australian football. A particularly innovative feature of this project is that, in addition to collecting effectiveness evidence, it will also direct significant research attention towards understanding: how sports safety policy is set, particularly at the community level; how consensus can be reached among sports safety experts in the community and sport governing body settings; and how evidence-based safety guidelines are best developed, packaged and delivered to community sport.

\section{BACKGROUND TO THE NOGAPS PROJECT}

It is critical that sports safety interventions have a strong evidence base. It is equally important that they are both effective from a public health perspective and can be readily adopted in the 'real world'. The impact of non-adoption on intervention effectiveness has been highlighted in recent RCT of lower limb injury prevention measures. ${ }^{14} 15$ Relevant to this project, the Federation Internationale de Football Association, the international body for soccer, recently developed The 11 . This programme, targeted at community sport, incorporates 10 evidence-based exercises (strength, balance, plyometric) and a fair-play principle as informed by scientific evidence for lower limb injury prevention. The emerging results from the first implementation studies for The 11 have shown limited success, however, because few of the targeted participants adopted the programme and there was a perception that it was not relevant to the real-world community sport setting in which it was implemented. ${ }^{16}$

Peak sports body consultations have confirmed that, to progress safety, they need support to translate scientific evidence into practical tools and approaches that they can adopt at a community sport level. ${ }^{1}$ Despite the availability of evidence-based interventions, it is clear that sports safety efforts are currently hampered because limited research attention has focused on understanding the intervention implementation context and processes, including barriers and facilitators to sustainable programmes. Most sports currently have an ad-hoc approach to safety, with limited adoption of policy and limited strategic planning or coordination of implementation efforts. $.^{5} \quad 17-20$ Studies in community sport show an increasing acceptance of safety policy, but widespread and consistent adoption of safety interventions is lacking. ${ }^{1721}$ Despite the availability of evidencebased interventions, they are not widely implemented and the reasons for this are unknown. ${ }^{3}$ This issue has been recognised as an international challenge for researchers. ${ }^{4-6}$
Our proposed research and partnership will: (1) establish and support a key stakeholder partnership from the outset; (2) develop an evidence-based strategic approach to lower limb injury prevention in community Australian football; and (3) develop and evaluate a strategic implementation plan designed to address key barriers and facilitators in community sport.

While there is a need to understand the implementation context across all sports, it is not feasible to do so within one project or funding timeframe. At the suggestion of the partner agencies, while developing a strategic approach with wide applicability, the programme will be specifically trialled within the sport of Australian football. Although the package will focus on injury prevention, it will also encourage participation and performance enhancement, as these aspects are important motivators for community sport engagement and are likely to be interrelated. The study will be conducted in Australian football because it:

1. is the second most popular participation sport in Australian men; ${ }^{22}$

2. has large numbers of both formal and informal community participants, including women and indigenous groups; ${ }^{23}$

3 . is delivered through strong networks of local clubs within regional leagues with common administration;

4. is arguably the best resourced and institutionalised sport in Australia in terms of its administrative, governance and management networks;

5. has a high media and public profile;

6. has structured training programmes provided by clubs and coaches;

7. has a strong focus on group participation and team building; and

8. is a relatively high-risk community sport for lower limb injury. ${ }^{24-28}$

From a public health perspective, Australian football-related lower limb injuries are a particular concern because of their high frequency, associated treatment/rehabilitation costs, absence from participation and other long-term outcomes. ${ }^{29}$ They can also stop players from continuing to reap the social and physical health benefits of being physically active and may discourage others from taking up the sport because of a fear of injury. ${ }^{30}$

Improving the safety of Australian football participation will result in considerable public health gains, through increased participation in physical activity, fewer medical presentations and reduced health costs. Prevention and safety programmes targeting key injuries would clearly be beneficial. Overall, lower limb injuries (hamstring injuries, lateral ligament sprains of the ankle, knee ligament ruptures and sprains, hip adductor muscle strains and calf muscle strains) are the predominant injuries reported in community Australian football. ${ }^{25} 31$ While not usually involving hospital, emergency or elective surgery services, muscle strain injuries (eg, hamstring strains) often require treatment from primary care health professionals (eg, physiotherapists, sports physicians, etc), result in significant periods of lost participation and have high recurrence rates. In contrast, knee ligament (especially anterior cruciate ligament) injuries result in significant healthcare costs through imaging and surgical management. These injuries result in high morbidity with extended periods of lost participation time, lengthy rehabilitation and a high risk of long-term morbidity such as osteoarthritis.

The prevention of all lower limb injuries is a priority area for Australian football stakeholders, ${ }^{32}$ and suggested methods for prevention have been largely built around the premise of improved player conditioning and preparation in the form of 
strengthening or functional training programmes developed in various football settings. ${ }^{14}$ 33-39 Given the incidence of lower limb injuries, the development, dissemination and implementation of evidence-based Australian football-specifc safety interventions targeting these injuries would be highly beneficial for reducing injury rates and both indirect and direct injury costs, as well as increasing safe participation. The efficacy of specific exercise interventions for lower limb injury have been trialled in Australian football and other sports by several of the authors of this study and others, providing an ideal background on which to develop an Australian football-specific programme. Authors CFF and DGL are completing a current NHMRCfunded RCT into the effectiveness of exercise interventions specifically to prevent knee injuries in Australian football, ${ }^{40}$ with the results of the RCT being available in 2011. Results from this NHMRC-funded study will provide important inputs into the NoGAPS Project.

Accumulated international evidence from both RCT and neuromuscular biomechanical studies shows that lower limb injuries can be prevented through targeted training incorporating structured warm-up, balance training, side-stepping/cutting skills and jump/landing training. ${ }^{34} 35$ 41-43 Indeed, players participating in pre-season training programmes or receiving specialist coaching are significantly less likely to be injured than other players. ${ }^{44}$ The aforementioned The 11 in soccer is the most developed international exercise training injury prevention programme. Many of the injuries targeted by The 11 are also common to Australian football and that programme provides an ideal base for the development of a similar programme specifically for community Australian football.

Several of the authors and others have undertaken and published a number of intervention studies with particular relevance to Australian football-related lower limb injuries. These strongly argue for the efficacy of exercise training programmes and thus provide a strong rationale for the Australian football safety programme to be developed in this project. Strategies to improve landing and recovery have been shown to decrease non-contact lower limb injuries. ${ }^{45}$ Eccentric exercise prevents hamstring muscle strains in Australian football and other football codes. ${ }^{38} 394647$ Plyometric, perturbation and skill exercises, as well as traditional proprioceptive exercises, prevent anterior cruciate ligament injury. ${ }^{33-35} 414849$ Similar exercises prevent ankle injuries. ${ }^{43}$

Overall, there is strong research evidence to inform the development of an Australian football exercise training intervention with a high likelihood of providing significant injury prevention benefits. Simple, easy to implement exercise training guidelines, if coupled with a carefully considered and robust delivery plan, are likely to have a high chance of successful uptake and injury reduction. Lessons learnt from a detailed examination of the processes for developing an evidence-based sports safety intervention and evaluation of its implementation, uptake and sustainability will provide a model for adoption by other sports.

\section{NOGAPS PROJECT OUTLINE}

The NoGAPS Project will be conducted over 4 years and five phases (see table 1). The specific aims of each study phase are outlined below, together with the proposed methods and approach. The NoGAPS Project has been framed within the RE-AIM framework's recent extension to community sport ${ }^{13}$ and an overall approach towards the conduct of implementation/effectiveness studies in sports injury research. ${ }^{50}$ Major programme outcome measures relating to the five RE-AIM domains of reach, effectiveness, adoption, implementation and maintenance will be determined. The study will be based around a randomised controlled ecological trial that assesses three lower limb injury intervention delivery modes in community level Australian football clubs: the supported, unsupported, and control programmes.

\section{Phase 1: developing evidence-based safety guidelines (2010-11)}

Any safety intervention needs to begin with evidence-based information about what is likely to be effective. Phase 1 will translate the available scientific evidence for lower limb injury prevention into formal, practical exercise training guidelines for dissemination to community clubs. Specific research questions are:

1. What are the specific lower limb injury prevention needs and priorities of community football clubs?

2. How can the evidence of effective lower limb injury prevention interventions be summarised for community sport?

3. What should be the content of exercise training guidelines for lower limb injury prevention in community Australian football?

4. What is the preferred format and presentation of the formal guidelines based on this evidence?

5. What is the process for reaching expert consensus on sports safety interventions and how could these processes be improved?

Questions 1-3 will be addressed through a systemic review of both peer review and the non-peer review 'grey' literature, including websites and reports. For questions 4 and 5, a qualitative research approach will be used to derive the specific research outcomes. A qualitative approach will also be used to gain insights into the processes of conducting each stage. To this end, all meetings and deliberations will be recorded and transcribed and an analysis of the consensus process documented. This approach has been successfully used by two of the authors to drive a process to collate evidence for falls prevention policy development. ${ }^{51}$ This phase will draw on the extensive networks of the AFL to link with its formal Australian Football League Sport Science Advisory Group (AFLSSAG), as a wider consultation group of experts.

Stage I will scope and summarise the evidence-base for exercise training programmes to prevent lower limb injury in Australian football. A summary profile of lower limb injuries in community

Table 1 Overview of study and study phases

\begin{tabular}{lll}
\hline Overall research and partnership goals & Project phase & Study year \\
\hline Develop evidence-based safety guidelines for lower limb injury in Australian football & 1 & $2010-11$ \\
Refine guidelines and develop a delivery plan & 2 & 2011 \\
Implement and evaluate guidelines and delivery plan & 3 & $2012-13$ \\
Develop and release of a national Australian football sports safety package & 4 & 2014 \\
Extension of sports safety package through national/state partners to other sports & 5 & 2014 \\
Promotion of general sports safety with partner agencies & 5 & $2010-14$ \\
\hline
\end{tabular}


club football will be generated from previously published studies. Information about the likely exercise training guideline components will be determined from the authors' previous work and a systematic review of the international literature. This information will be collated and presented to an expert panel (consisting of all authors and the AFL) that will meet face to face and then via teleconference or electronically to develop a first draft of the exercise training guidelines.

Stage II will involve wider consultation with the AFLSSAG using a Delphi consultation process. ${ }^{52}$ The Delphi participants will be purposively selected from those who hold state or national positions with responsibility for the development, design and implementation of sports science-based training programmes in high performance Australian football clubs. The homogenous Delphi panel will have approximately 15 participants and a three-round online survey will be conducted. The first round will present the draft guidelines and ask the group to provide feedback on their content and focus. Subsequent rounds will build on the most common responses until a high level of consensus is reached ( $>75 \%$ of panel members agreeing). There will be an initial face-to-face meeting of the research team with the Delphi panel to explain the context and purpose of the guidelines.

Stage III will involve the expert panel reviewing the guidelines, drawing on the Delphi consensus consultations and agreeing on the content and design of the final guideline formats, through face-to-face meetings, teleconferences and/or electronic means. The output will be evidence-based, expert consensusagreed exercise guidelines and pertinent information aimed at community Australian football.

\section{Phase 2: refine guidelines and develop a delivery plan (2011)}

Phase 2 will develop a delivery plan for the guidelines developed in phase 1 and obtain community feedback on the content and format of both. Specific questions to be addressed include:

1. To what extent are the developed exercise training guidelines able to be fully understood, and likely to be implemented, by community Australian football?

2. How should the guidelines be 'packaged' to ensure relevance to community Australian football clubs and contribute to maximal adoption and implementation?

3. What other documentation and support (eg, training, policy, resources, etc) are likely to be needed to disseminate the developed guidelines with high reach?

As with much of phase 1, a qualitative research approach will be adopted. This will depend on contributions from our partner agencies through the expert panel and the extensive networks of our AFL and NSWSIC partners for access to community sports groups. All meetings and deliberations will be recorded and transcribed and an analysis of the consensus process documented.

Stage I will involve consultation with community club representatives to obtain feedback on the draft guidelines (content, format, language, etc) and to inform a feasible delivery plan. These consultations will be via focus group discussions ${ }^{53}$ involving representatives of the typical Australian football club personnel and members who make safety decisions and implement interventions. It is anticipated that this will require approximately six to eight focus groups, each with 10-12 participants representing a mix of key safety actors at the community club level (eg, coaches, administrators, first aid providers, parents, players, etc). All focus groups will be taped, transcribed and results thematically analysed with $\mathrm{N}$-vivo. As phase 3 will be conducted in Victoria, which is a state of
Australia and the one with the highest number of Australian football registered players, this phase 2 stage will be largely conducted in Australian football teams from another Australian state, New South Wales. This will limit contamination for the subsequent RCT, through unintentional leakage of the exercise guidelines to leagues/clubs before the trial.

Stage II will consider the focus group outcomes to refine the guidelines as necessary. In addition, the expert panel will develop a recommended delivery plan in the light of the focus group feedback and prepare the full Australian football safety programme for delivery in the subsequent year.

\section{Phase 3: implement and evaluate guidelines and delivery plan (2012-13)}

Phase 3 will evaluate the delivery of the Australian football safety programme in community Australian football to understand the processes, enablers and barriers of implementing new evidence-based safety interventions in community sport. In doing so, the NoGAPS Project will provide international and national leadership in the conduct of implementation research in community sport and for developing processes to guide locallevel sports policy development and the sustainable adoption/ implementation of evidence-based interventions. A randomised controlled ecological design will be used to compare two delivery modes (supported and unsupported) against usual practice (control) in community clubs. The RE-AIM community sports extension ${ }^{13} 50$ will be used to underpin the evaluation. Specific questions to be addressed are:

1. What formal lower limb injury prevention policies and practices do community Australian football clubs adopt/ implement, under different package delivery modes?

2. Does providing a supported delivery plan change the commitment to, and implementation of, lower limb injury prevention policies and practices in community clubs, compared with unsupported plans or usual practice?

3. What factors are most predictive of sustainable intervention implementation, or otherwise, under different delivery modes?

4. How does intervention uptake/adoption/implementation influence injury rates in community clubs, under different delivery modes?

5. What enables or impedes sustainable intervention implementation within the real-world community sport setting?

6. What is the optimal process/mix of activities to support community clubs to uptake evidence-based safety guidelines?

7. How can research evidence be successfully translated to community clubs through a specific set of evidence-informed guidelines?

\section{Study design and sampling}

A group-clustered ecological RCT will be conducted over 2 years, with a particular focus on measuring the Australian football safety participation and performance package reach, effectiveness, adoption and implementation in year 2 and on the same factors plus maintenance in year 3. A cluster randomisation design is optimal for sports safety studies, ${ }^{54}$ and has been used by the authors in other Australian football RCTs. ${ }^{40} 55$ It will be conducted in three community football leagues from three well-defined geographical regions in Victoria, each with a representative and strong microcosm of community Australian football of comparable standard and community delivery. In choosing the leagues, consideration will be given towards:

a. geographical location in relation to where the main research team is based; 
b. having a mix of metropolitan, regional and rural clubs as this will impact on resources, ability to gain assistance, willingness to engage, etc;

c. similar sports delivery issues to those in other parts of the country where community football is delivered, including size of the league as this will impact on the number of employees and volunteers available to support the programme;

d. having established links with the research team;

e. having large numbers of relevant teams and registered players, across a range of competition levels; and

f. level of professionalism of the league and its ability to pay players.

This aspect of the NoGAPS Project will draw heavily on the existing extensive networks and influence of our AFL and VicHealth partners with community football clubs. The chief executive officers of both Australian Football Victoria and the Victorian Country Football League have been consulted and expressed a keen interest in being active partners in it to facilitate the involvement of relevant leagues and teams. Discussions have already been held with the Ballarat Football League (approximately 30 teams, >1400 players) and the Geelong Football League (approximately 40 teams, >1200 players); both are fully supportive of the NoGAPS Project and expressed an interest in participating. All players will be aged over 16 years, and play in teams ranging from under-18 to open age groups.

Each league will be randomly allocated to one of three delivery arms. The league is the unit of randomisation because it represents a single Australian football competition with many clubs participating in it on a regular basis, and is an independently contained context for sport policy development and implementation. Each league has its own management structure and accountability back to state and national Australian football bodies. Within leagues, all clubs will be invited to participate. Each club is responsible for a number of teams and has its own management structure and sports safety processes. The first hierarchical level will therefore be leagues, the second will be the clubs within those leagues, and the third will be the teams of players. The RE-AIM domains will be evaluated within each tier. ${ }^{13} 50$ The effectiveness of the Australian football safety participation and performance package will largely be assessed directly with players, as the anticipated injury/health benefits/ outcomes will be in individual players within the teams. By exposing all clubs within a specific league to the same delivery mode, the chances of contamination across clubs/teams will be minimised. Nonetheless, some of the measures to be collected will include information about potential contamination and broader awareness of the Australian football safety participation and performance package and other resources delivered by the partners. While is it expected that the clubs across the three leagues will be similar with regard to key factors, club characteristics will be collected at baseline and adjusted for in the analyses should imbalance exist. By allocating the intervention to leagues rather than clubs, no specific club (within a league) will be advantaged or disadvantaged in terms of performance or injury prevention benefits.

This study adopts a broad ecological design (in that regions/ leagues are allocated to different delivery modes) and the focus is on understanding the key drivers of intervention uptake, implementation and maintenance. Therefore, usual sample size calculations based on formal hypothesis testing for RCT are not appropriate. We have chosen three leagues because we want to compare two delivery modes (supported and unsupported) against a control (or current practice). Based on our current community football research undertaken in the Ballarat Football
League (with $100 \%$ recruitment of all invited clubs), ${ }^{40}$ we anticipate very high participation from clubs in the proposed study. Even if the response was a worst case scenario of $50 \%$ of all clubs/players, we still expect to have more than 15 teams and over 700 players from each league involved. Assuming that weekly training sessions and games accumulate to $4 \mathrm{~h} /$ week, over a 20 -week season and a 6-week pre-season (training only), this corresponds to monitoring injuries and safety practices over $30750 \mathrm{~h}$ in each league per year.

\section{Delivery modes to be compared}

Delivery outcomes and processes associated with the Australian football safety programme will be evaluated by comparing the RE-AIM domains across the three delivery modes, with one league allocated to each delivery mode. Modes 1 and 2 will be delivered over 2 years, to enable assessment of sustainability. To our knowledge, no published research study has evaluated sports injury intervention maintenance for more than 12 months within sports clubs/teams.

Mode 1: Supported Programme. Clubs in this league will receive the evidence-based guidelines with a fully supported delivery package. This support will be determined in phase 2 but is expected to include: written and electronic resources, telephone support, visits by research team, direct assistance with programme delivery for a limited number of training sessions, education of coaches and club personnel, etc.

Mode 2: Unsupported programme. Clubs in this league will receive the developed guidelines with minimal advice on how to implement them and without support. The rationale for this study arm is the concern that community clubs may only be willing and able to implement an evidence-based intervention if they are fully supported to do so.

Mode 3: Control. In year 2, clubs will be monitored under their current safety policies and practices. While providing a control arm against which to compare the two active delivery modes, this will also enable investigation of the extent to which safety activities promoted by our partners (SMA, JLT Sport and VicHealth) have reached community sport under their existing dissemination approaches. In year 3, the clubs in this league will be asked to deliver the exercise-based guidelines under a best mix of strategies, as indicated from the year 2 comparison of delivery arms. This will enable comparison of new adopters (clubs/ players) with those associated with a sustained programme of more than 1 year.

\section{Data collection processes}

All field-based data collection processes for the injury surveillance, exposure monitoring and collection of RE-AIM dimensions (such as adoption) have already been pilot tested and used in other Australian football injury prevention RCT and cohort studies by the authors. ${ }^{25-27} 31$ 55-60 An assessment of coach, player and league/club personnel attitudes, knowledge and behaviours will be undertaken before, during and after the Australian football safety participation and performance package delivery, based on the authors' previous Australian football studies. ${ }^{173258}$ 61-64 Within each delivery arm, a coordinator will collect data for the RE-AIM domains according to rigidly standardised data collection procedures. A detailed and targeted data collection procedures manual, containing the standardised data collection forms to record and code the exposure and RE-AIM evaluation data, and instructions on the web-based injury surveillance system (Injury Tracker provided by partner SMA - visit http://sportsinjurytracker.com.au/) will be given to coordinators and the participating league/clubs. 
Within each delivery mode, the five major RE-AIM dimensions of the Australian football safety programme will be assessed across the four league tiers. The specific RE-AIM evaluation measures will be developed in conjunction with the delivery plan in phase 2 but will be appropriate to the delivery tier:

a. leagues (eg, communication strategies, education/training provided, safety committee structures and monitoring processes, documented decision processes, key personnel attitudes/knowledge, etc);

b. clubs (eg, policy development/implementation/monitoring, policy infrastructure, coach training/support; sports administrative support/monitoring, promotion and communication, club administrator attitudes/knowledge of, etc);

c. teams (eg, guideline implementation, coach plans/practices, coach attitudes/knowledge, documentation processes; communication strategies, etc); and

d. participants (eg, players exposed to guidelines, players incorporating guidelines into their training routines, injury outcomes/rates, etc).

Qualitative data as suggested by the sports RE-AIM exten$\operatorname{sion}^{13} 50$ will be collected and content analysed to identify themes and the data categorised according to such themes. Responses will be scored and the scores from different items combined to give overall scores on quasi-continuous scales, which will then be analysed and compared across delivery modes by generalised linear modelling techniques, adjusting for clustering effects and baseline inequalities, as required. The effectiveness of the Australian football safety programme will be assessed through injury surveillance and exposure monitoring. A team nominee will enter all injury details into a web-based injury database, Injury Tracker, on a weekly basis. SMA will provide the research team with electronic data from Injury Tracker. Poisson or negative binomial regression will be used to compare injury rates and their trends across delivery modes, with adjustment for key factors.

The data collection methods will be validated throughout the study. Postgraduate research students will undertake associated projects to collect the injury and exposure data independently and/or to observe the actual safety practices of leagues/clubs to compare against the self-reported information. Partner JLT Sport will provide an electronic database of all injury claims from participating clubs during the study period for external comparison with the NoGAPS Project's injury surveillance records. Through its risk management programme, JLT Sport will also conduct an independent annual audit of the broad safety policies and practices of all clubs across the leagues during the NoGAPS Project.

\section{Phase 4: development and release of a national Australian football safety programme (2014)}

Phase 4 will take the lessons learnt from phase 3 to develop and implement a national policy action plan for the prevention of lower limb injuries in Australian football. Specific questions are:

1. What should be the content and format of a national policy/ action plan to support exercise training guidelines to prevent lower limb injury in community Australian football?

2. How could this be best integrated into existing structures to support community Australian football safety?

Stage I will refine the Australian football safety participation and performance package for national roll-out, according to the outcomes of phase 3 . This will be ratified by the same expert panel as in phases $1 / 2$. The panel will meet face to face and conduct discussion via teleconference or electronic means. The final Australian football safety programme will also be given to the AFLSSAG for feedback, which will be achieved through online surveying until consensus is reached, through a Delphi consultation process, using the same methods as outlined for phase 1.

Stage II will format the final version of the Australian football safety programme appropriately and make it available online through our Australian football partner's website for community clubs to download and provide feedback on. The feedback process will be facilitated by an online survey on the Australian football website. All feedback will be collated and analysed by the research team and fed back to the AFL so that it can be taken into account before the full formal release of the Australian football safety programme by the AFL.

Stage III will involve setting a national AFL policy/action plan based on procedures for clubs to adopt to prevent lower limb injury and formal release of the final product. Links to the supporting activities of all the other partners in this project will also be made, to ensure that all agencies distribute a consistent message about Australian football lower limb injury prevention. It is expected that a multiagency response from our partners will enhance the long-term success of the Australian football safety programme. This process will be documented and analysed to develop an understanding of why, how and when specific decisions were made.

\section{Phase 5: extension to national/state sports safety (2010-14)}

Phase 5 will consider the potential to modify and adapt the Australian football safety programme to other sports for safe sustained participation across a range of activities. Separate consideration will be given to the evidence-informed exercise training guidelines and the delivery plan components. Specific questions to be addressed are:

1. Which sports are most likely to benefit from (a) adaption of the specific exercise training for lower limb injury prevention guidelines and (b) the evaluated delivery plan?

2. What are the key components to delivering evidence-based lower limb injury prevention guidelines that could be used to inform a state/national strategic approach to implementing other safety or health promotion interventions in the community sport setting?

3. What unique, but complementary, role could each partner agency play in a future strategic approach to sports safety?

In 2014, the outcomes of phases 1-3 will be used by each partner agency to review the delivery of their sports safety interventions. Research team members will participate in discussions with partner agencies to identify potential roles in any future strategic approaches (which will be determined from the results of previous phases). This process will be documented and analysed to develop an understanding of why, how and when decisions were made.

A literature review of injury risk and evidence-based interventions in popular non-Australian football sports will be undertaken to assess the direct relevance of the exercise training guidelines to those sports. Moreover, partner JLT Sport will provide insurance claim data for a range of sports they provide insurance cover for (eg, netball, soccer, cricket, gymnastics) to help identify priority sports and injury prevention targets. Lessons learnt from the intervention delivery in community Australian football will be reviewed and the direct relevance to other sports will be identified by the research team and the partner agencies. Through the partner agency networks (VicHealth, SRV, NSWSIC, JLT Sport) a series of two to three consultation meetings between the research team, the partners 
and these other sports will also be held to agree on a way forward.

Although the main focus on the extension to national/state policy/action plans for other sports will be in 2014, many background activities leading to this will be conducted in 2010-13 as joint activities of the researchers and partner agencies. These activities will increase the profile of, and acceptance for, sports safety activities within community sport more generally. They will also generate background support for sports safety within the culture of community sport and knowledge and awareness among a range of relevant consumers. These activities will include fostering and encouraging research into the translation of sports safety evidence through specific scientific sessions at Australia's major sports medicine conference. These sessions will be set and chaired by the research team and funded by SMA. We will work with our partner agencies (VicHealth, NSWSIC, SRV, SMA) to plan and deliver sports safety and injury risk management forums for community sport delivery bodies and participants. In addition, researchers will work with partner agencies (SMA, SRV, VicHealth, NSWSIC) to write and publish regular plain language articles describing latest advances in sport safety targeted at these same audiences.

\section{LIKELIHOOD TO INFLUENCE HEALTH AND RESEARCH POLICY}

The public health significance of sports injuries has long been recognised in Australia. ${ }^{2} 65$ The Commonwealth Department of Health's first national strategy for injury prevention ${ }^{66}$ included sports injury prevention as a key target. Australia currently has no national sports safety policy, partnership or action plan, although the aims of this project are in agreement with those of the Commonwealth government's more broadly focused national injury prevention plan. ${ }^{67}$ It is expected that this project will inform the development of sports safety components for updates to this plan and also to the plans and activities of other relevant state and federal governments (eg, health, sport and recreation). Recent evidence from national and state-specific injury data collections ${ }^{28} 68-70$ continues to highlight the burden of sports injuries, their significant impact on health service delivery, and their potential to be associated with sociodemographic health inequalities. ${ }^{71}$ Moreover, sports injuries are a major barrier towards sustained health-related lifelong physical activity participation in Australia. ${ }^{30} 7273$

Commensurate with the size of this public health burden, considerable effort has been directed towards identifying the causes of sports injury and potential preventive measures. ${ }^{6} 7475$ Although systematic reviews (eg, Parkkari et al) ${ }^{76}$ highlight accumulating evidence for the efficacy of sports injury prevention interventions, they often imply that the weight of evidence is sufficient to ensure the uptake of 'proven' measures. Recent studies show that when these interventions are implemented into real-world community sports settings, they are not effective. There is a very real need to evaluate the effectiveness of sports safety interventions in the real-world context of sports delivery, even if their efficacy has already been demonstrated in RCTs, to maximise public health impact. ${ }^{50}$

In 2008, the Australian government released it new directions paper 'Australian sport: emerging challenges, new directions'. 77 Accompanying this was a new government action of shifting its sport portfolio into the health portfolio. This will benefit sports by increasing physical activity levels, and by fully aligning sport within a preventive health approach. In this, Australia is showing international leadership. Linking sport with health should also enable greater attention to be given to the major barrier towards sustained physical activity participation, particularly that of sports injury. Participation in sport and physical activity will only be sustained in the long term if it is delivered in a safe way to minimise injury risk. ${ }^{30}$ Given this new focus for the Australian Department of Health and Ageing, it is timely to explore how a safety promotion focus could be harnessed within broader preventive health promotion initiatives to ensure safe physical activity participation for all. (After this project was approved for funding, in mid-2010 the sport portfolio of the Australian government was transferred to the Department of the Prime Minister and Cabinet).

Previous sports safety efforts have largely been undertaken in isolation, by either the health or the sport sectors, and this has probably limited their success. Given the new and enhanced links between sport and health, this project will inform ongoing developments and directions for national/state approaches to sports safety policy and practice. This will necessarily involve national and local sporting organisations, as well as government bodies and both health promotion and sports medicine agencies. It will build on previous policy developments in sports safety at the national level, ${ }^{23}$ as well as initiatives already implemented by sports bodies.

With regard to setting and addressing research agendas, this project tackles an internationally recognised gap. ${ }^{4-6}$ It will drive new research directions and set international standards for the conduct of sports safety research ensuring demonstrable impacts on the safety of sport for all involved. A major strength of the research team is its collective extensive experience in the conduct and publication of research into: sports safety; injury surveillance; injury prevention; exercise and training programme development and understanding of injury mechanisms. Members of our research team include the national leaders in sports injury prevention and in Australian football-specific research.

Funding This study protocol is funded by a National Health and Medical Research Council (NHMRC) partnership project grant (ID 565907) with additional support (both cash and in kind) from the project partner agencies: the Australian Football League (AFL); Victorian Health Promotion Foundation (VicHealth); NSW Sporting Injuries Committee (NSWSIC); JLT Sport, a division of Jardine Lloyd Thompson Australia Pty Ltd; the Department of Planning and Community Development - Sport and Recreation Victoria Division (SRV); and Sports Medicine Australia - National and Victorian Branches (SMA). CFF is supported by a NHMRC principal research fellowship (ID 565900). BJG is supported by an NHMRC career development award (ID 465103). The Australian Centre for Research into Injury in Sport and its Prevention (ACRISP) is one of the international research centres for prevention of injury and protection of athlete health supported by the International Olympic Committee (IOC). The funding partners provided editorial input into the protocol.

\section{Competing interests None.}

Contributors The list of authors represents the order in which people were named on the funding application. It is not necessarily the same as the order of contribution to the protocol development.

Provenance and peer review Not commissioned; externally peer reviewed.

\section{REFERENCES}

1. Poulos R, Donaldson A, Finch C. Towards evidence informed sports safety policy for NSW, Australia: assessing the readiness of the sector. Inj Prev 2010;16:127-31.

2. Finch C, McGrath A. SportSafe Australia: a national sports safety framework. A report prepared for the Australian Sports Injury Prevention Taskforce. Canberra: Australian Sports Commission, 1997.

3. Department of Health and Ageing. Sports safety in Australia. An update. July 2003. Australian Government Department of Health and Ageing, Canberra, Australia; 2004.

4. Finch C. A new framework for research leading to sports injury prevention. J Sci Med Sport 2006;9:3-9.

5. Timpka T, Finch C, Goulet $C$, et al. Meeting the global demand of sports safety the role of the science and policy intersection for sports safety. Sports Med 2008;39:795-805.

6. van Tiggelen D, Wickes $S$, Stevens $V$, et al. Effective prevention of sports injuries: a model integrating efficacy, efficiency, compliance and risk taking behaviour. $\mathrm{Br} \mathrm{J}$ Sports Med 2008:42:648-52. 
7. Glasgow R, Vogt T, Boles S. Evaluating the public health impact of health promotion interventions: the RE-AlM framework. Am J Public Health 2001;89:1322-7.

8. Glasgow R, Lichtenstein E, Marcus A. Why don't we see more translation of health promotion research to practice? Rethinking the efficacy-to-effectiveness transition. Am J Health Promotion 2003;93:1261-7.

9. Li F, Harmer P, Glasgow R, et al. Translation of an effective tai chi intervention into a community-based falls-prevention program. Am J Public Health 2008;98:1195-8.

10. Gyurcsik NC, Brittain DR. Partial examination of the public health impact of the People with Arthritis Can Exercise (PACE) program: reach, adoption, and maintenance. Public Health Nurs 2006;23:516-22.

11. Besculides $\mathbf{M}$, Zaveri $\mathrm{H}$, Hanson $\mathrm{C}$, et al. Best practices in implementing lifestyle interventions in the WISEWOMAN program: adaptable strategies for public health programs. Am J Health Promot 2008;22:322-8.

12. Dzewaltowski D, Estabrooks $P$, Klesges $L$, et al. Behavior change intervention research in community settings: how generalizable are the results? Health Promot Int 2004:19:235-45.

13. Finch CF, Donaldson A. A sports setting matrix for understanding the implementation context for community sport. Br J Sports Med 2010;44:973-8.

14. Engebretsen AH, Myklebust G, Holme I, et al. Prevention of injuries among male soccer players: a prospective, randomized intervention study targeting players with previous injuries or reduced function. Am J Sports Med 2008:36:1052-60.

15. Steffen K, Myklebust G, Olsen 0, et al. Preventing injuries in female youth football - a cluster-randomized controlled trial. Scand J Med Sci Sports 2008;18:605-14.

16. Kilding AE, Tunstall H, Kuzmic D. Suitability of FIFA's "The 11" training programme for young football players-impact on physical performance. J Sports Sci Med 2008; 7:320-6.

17. Casey M, Finch C, Mahoney M, et al. Sport safety policies and practices in two rural Victorian communities. J Sci Med Sport 2004:7:226-31.

18. Donaldson A, Forero R, Finch C. The first aid policies and practices of community sports clubs in northern Sydney, Australia. Health Promot J Aust 2004:15:155-61.

19. Donaldson A, Forero R, Finch C, et al. A comparison of the sports safety policies and practices of community sports clubs during training and competition in northern Sydney, Australia. Br J Sports Med 2004;38:60-3.

20. Abbott K, Klarenaar P, Donaldson A, et al. Evaluating SafeClub: can risk management training improve the safety activities of community soccer clubs? $\mathrm{Br} \mathrm{J}$ Sports Med 2008:42:460-5.

21. Swan $\mathbf{P}, 0$ Otago L, Finch $C$, et al. The policies and practices of sports governing bodies in relation to assessing the safety of sports grounds. J Sci Med Sport 2009:12:171-6

22. Australian Sports Commission, Department of Health and Ageing. Participation in exercise, recreation and sport. Canberra: Australian Government, 2008.

23. Australian Bureau of Statistics. Sport and recreation: a statistical overview, Australia, 2007 (Edition 1). Catalogue no. 4156.0. Canberra: Australian Bureau of Statistics, 2007.

24. Gabbe B, Finch C. A profile of Australian football injuries presenting to sports medicine clinics. J Sci Med Sport 2001;4:386-95.

25. Braham R, Finch C, McIntosh A, et al. Community level Australian football: a profile of injuries. J Sci Med Sport 2004:7:96-105.

26. Gabbe B, Finch $\mathrm{C}$, Wasjswelner $\mathrm{H}$, et al. Predictors of lower extremity injuries at the community level of Australian football. Clin J Sport Med 2004;14:56-63.

27. McManus A, Stevenson M, Finch C, et al. Incidence and risk factors for injury in non-elite Australian Football. J Sci Med Sport 2004;7:384-91.

28. Flood L, Harrison J. Hospitalised sports injury, Australia 2002-2003. Injury research and statistics series number 27. Adelaide: Australian Institute of Health and Welfare, 2006.

29. Gabbe B, Finch C, Cameron P. Priorities for reducing the burden of injuries in sport: the example of Australian football. J Sci Med Sport 2007;10:273-6.

30. Finch $\mathbf{C F}$, Owen N. Injury prevention and the promotion of physical activity: what is the nexus? J Sci Med Sport 2001:4:77-87.

31. Gabbe B, Finch C, Wajswelner $\mathrm{H}$, et al. Australian football: injury profile at the community-level. J Sci Med Sport 2002;5:149-60.

32. Gabbe B, Finch $\mathrm{C}$, Wajswelner $\mathrm{H}$, et al. Does community-level Australian football support injury prevention research? J Sci Med Sport 2003;6:231-6.

33. Dempsey A, Lloyd D, Elliott B, et al. The effect of technique change on knee loads during sidestep cutting. Medi Sci Sports Exerc 2007;39:1765-73.

34. Cochrane JL, Lloyd DG, Besier TF, et al. Training affects knee kinematics and kinetics in cutting maneuvers in sport. Med Sci Sports Exerc 2010;42:1535-44.

35. Dempsey AR, Lloyd DG, Elliott BC, et al. Changing sidestep cutting technique reduces knee valgus loading. Am J Sports Med 2009;37:2194-200.

36. Askling C, Karlsson J, Thorstensson A. Hamstring injury occurrence in elite soccer players after preseason strength training with eccentric overload. Scand J Med Sci Sports 2003;13:244-50.

37. Verrall G, Slavotinek J, Barnes P. The effect of sports specific training on reducing the incidence of hamstring injuries in professional Australian Rules football players. Br J Sports Med 2005:39:363-8.

38. Brooks J, Fuller C, Kemp S, et al. Incidence, risk, and prevention of hamstring muscle injuries in professional Rugby Union. Am J Sports Med 2006;34:1297-306.
39. Gabbe B, Branson R, Bennell K. A pilot randomised controlled trial of eccentric exercise to prevent hamstring injuries in community-level Australian football. J Sci Med Sport 2006;9:103-9.

40. Finch C, Lloyd D, Elliott B. The Preventing Australian Football Injuries with Exercise (PAFIX) study — a group randomised controlled trial. Inj Prev 2009;15:e1. Available from 10.1136/ip.2008.021279.

41. Lloyd D. Rationale for training programs to reduce anterior cruciate ligament injuries in Australian football. J Orthop Sports Phys Ther 2001;31:645-54.

42. Verhagen $\mathbf{E}$, van $\operatorname{der}$ Beek $A$, Twisk $J$, et al. The effect of a proprioceptive balance board training program for the prevention of ankle sprains: a prospective controlled trial. Am J Sports Med 2004;32:1385-93.

43. Olsen 0, Myklebust G, Engebretsen L, et al. Exercises to prevent lower limb injuries in youth sports: cluster randomised controlled trial. BMJ 2005;330:449.

44. Stevenson M, Finch C, Hamer P, et al. The Western Australian sports injury study. Br J Sports Med 2003;37:380-1.

45. Scase E, Cook J, Madkissi M, et al. Teaching landing skills in elite junior Australian football: evaluation of an injury prevention strategy. Br J Sports Med 2006:40:834-8.

46. Brockett C, Morgan D, Proske U. Human hamstring muscles adapt to eccentric exercise by changing optimum length.. Med Sci Sports Exerc 2001;33:783-90.

47. Arnason A, Andersen T, Holme I, et al. Prevention of hamstring strains in elite soccer: an intervention study. Scand J Med Sci Sports 2008;18:40-8.

48. Caraffa A, Cerulli G, Projetti M, et al. Prevention of anterior cruciate ligament injuries in soccer: A prospective controlled study of proprioceptive training. Knee Surg Sports Traumatol Arthrosc 1996;4:19-21.

49. Fitzgerald GK, Axe MJ, Snyder-Mackler L. The efficacy of perturbation training in nonoperative anterior cruciate ligament rehabilitation programs for physical active individuals. Phys Ther 2000:80:128-40.

50. Finch C. Chapter 16: Implementing studies into real life. In: Verhagen E, van Mechelen W, eds. Sports injury research: Oxford University Press, 2009:213-35.

51. Finch C, Day L, Donaldson A, et al. Determining policy-relevant formats for the presentation of falls research evidence. Health Policy 2009;93:207-13.

52. Hasson F, Keeney S, McKenna HR. Research guidelines for the Delphi survey technique. J Adv Nurs 2000;32:1008-15.

53. Krueger R, Casey M. Focus groups: a practical guide for applied research. 3rd edn Thousand Oaks, CA: Sage, 2000.

54. Emery CA. Considering cluster analysis in sport medicine and injury prevention research. Clin J Sport Med 2007:17:211-14.

55. Finch C, Braham R, Mclntosh A, et al. Should football players wear custom fitted mouthguards? Results from a group randomised controlled trial. Inj Prev 2005;11:242-6.

56. Gabbe B. Risk factors for lower limb injuries at the community-level of Australian football [PhD Thesis]. University of Melbourne, 2002.

57. Braham R, Finch C, McCrory P. Sports trainers have accurate but incomplete recall of injury details. Br J Sports Med 2003:37:561

58. Braham R, Finch C. Do community football players wear allocated protective equipment? Descriptive results from a randomised controlled trial. J Sci Med Sport 2004;7:216-20.

59. Braham R, Finch C, McCrory P. Non participation in sports injury research: why football players contribute to research projects. Br J Sports Med 2004;38:238-9.

60. Gabbe B, Finch C, Bennell K, et al. Risk factors for hamstring injuries in community level Australian football. Br J Sports Med 2005;39:106-10.

61. Finch C, Donohue S, Garnham A, et al. The playing habits and other commitments of elite junior Australian football players. J Sci Med Sport 2002;5:266-73.

62. Finch C, Donohue S, Garnham A. Safety attitudes and beliefs of junior Australian football players. Inj Prev 2002:8:151-4.

63. Finch C, McIntosh A, McCrory P, et al. A pilot study of the attitudes of Australian rules footballers towards protective headgear. J Sci Med Sport 2003;6:505-11.

64. Braham R, Finch C, Mclntosh A, et al. Community football players' attitudes towards protective equipment-a pre-season measure. Br J Sports Med 2004;38:426-30

65. Commonwealth Department of Health and Family Services and Australian Institute of Health and Welfare. National health priority areas report: injury prevention and control 1997. Canberra: Department of Health and Family Services and Australian Institute of Health and Welfare, 1998.

66. Commonwealth Department of Human Services and Health. Better health outcomes for all Australians. National goals, targets and strategies for better health outcomes into the next century. In: Prior M, ed. Canberra: Australian Government Publishing Service, 1994

67. National Public Health Partnership (NPHP). The national injury prevention and safety promotion plan: 2004-2014. Canberra: NPHP. 2004.

68. Cassell E, Finch C, Stathakis V. Epidemiology of medically treated sport and active recreation injuries in the Latrobe Valley, Victoria, Australia. Br J Sports Med 2003; 37:405-9.

69. Gabbe BJ, Finch CF, Cameron PA, et al. Incidence of serious injury and death during sport and recreation activities in Victoria, Australia. Br J Sports Med 2005; 39:573-7.

70. Boufous S, Dennis R, Finch C. A profile of hospitalisations and deaths due to sport and leisure injuries in New South Wales, 2000-2004. Sydney, Australia: NSW Injury Risk Management Research Centre, 2006. http://www.irmrc.unsw.edu.au/ documents/irmrcSportsInjuryReport.pdf. (accessed 20 Dec 2010). 


\section{Study protocol}

71. Finch C, Boufous S. Sports/leisure injury hospitalisation rates in New South Wales-evidence for an excess burden in remote areas. J Sci Med Sport 2008:12:628-32.

72. Finch C, Owen N, Price R. Current injury or disability as a barrier to being more physically active. Med Sci Sports Exerc 2001;33:778-82.

73. Finch C, Cassell E. The public health impact of injury during sport and active recreation. J Sci Med Sport 2006;9:490-7.

74. Bahr $\mathbf{R}$, Krosshaug T. Understanding injury mechanisms: a key component of preventing injuries in sport. Br J Sports Med 2005;39:324-39.
75. Meeuwisse WH, Tyreman H, Hagel B, et al. A dynamic model of etiology in sport injury: the recursive nature of risk and causation. Clin J Sport Med 2007:17:215-19.

76. Parkkari J, Mujala U, Kannus P. Is it possible to prevent sports injuries? Review of controlled clinical trials and recommendations for future work. Sports Med 2001:31:985-95.

77. Australian Government. Australian Sport: emerging challenges, new directions, 2008. http://www.health.gov.au/internet/main/publishing.nst/Content/sportaustralian-sport (accessed 18 Nov 2010). 


\section{Towards a national sports safety strategy: addressing facilitators and barriers towards safety guideline uptake}

Caroline F Finch, Belinda J Gabbe, David G Lloyd, et al.

Inj Prev 2011 17: 1-10 originally published online February 22, 2011 doi: 10.1136/ip.2010.031385

Updated information and services can be found at:

http://injuryprevention.bmj.com/content/17/3/1.full.html

These include:

References This article cites 64 articles, 26 of which can be accessed free at: http://injuryprevention.bmj.com/content/17/3/1.full.html\#ref-list-1

Email alerting Receive free email alerts when new articles cite this article. Sign up in service the box at the top right corner of the online article.

Topic Articles on similar topics can be found in the following collections Collections

Notes

To request permissions go to:

http://group.bmj.com/group/rights-licensing/permissions

To order reprints go to:

http://journals.bmj.com/cgi/reprintform

To subscribe to BMJ go to:

http://group.bmj.com/subscribe/ 